\title{
CONTRIBUIÇÃO À ORGANIZAÇÃO DE SERVIÇOS DE TRANSPLANTES DE MEDULA ÓSSEA E À ATUAÇÃO DO ENFERMEIRO
}

Sueli Riul*

Este trabalho é um estudo bibliográfico sobre a temática: transplante de medula óssea com ênfase na atuação do enfermeiro, levantada em publicações de enfermagem dos últimos dez anos.

As informações, organizadas e sintetizadas permitiram identificar que para realização do transplante de medula óssea são necessários, uma infra-estrutura apropriada com unidade de internação especializada capaz de atender ao menos dois pacientes concomitantemente, serviço ambulatorial e serviços complementares específicos como bancos de sangue e laboratórios apropriados. São necessários ainda recursos humanos especializados que se organizem em uma equipe multiprofissional capaz de prestar assistência adequada ao paciente. Os recursos operacionais através do planejamento, viabilizam esta assistência promovendo inter-relacionamento entre os recursos humanos e aproveitamento ótimo da infra-estrutura assegurando um mínimo de dez a vinte transplantes ao ano.

Foi possivel identificar também a atuação do enfermeiro nesse procedimento terapêutico. Esta se dá em todas as fases do processo de assistência ao paciente submetido a transplante de medula óssea, de modo peculiar em cada uma delas, sendo que nos periodos pré e pós-transplante, a atuação a nível ambulatorial está voltada ao acompanhamento, orientação e observação. Nos períodos de preparo imediato para o transplante, na sua realização e no período pós-transplante imediato, quando o paciente está internado, a atuação do enfermeiro está voltada para a assistência direta do paciente, preferentemente de forma individualizada e integral, na proporção máxima de um enfermeiro para dois pacientes.

* Dissertação (Mestrado em Enfermagem Fundamental). Escola de Enfermagem de Ribeirão Preto da Universidade de São Paulo. 1995, 109 p. Orientadora: Prof ${ }^{a}$ Dra $^{a}$ Olga Maimoni Aguillar. 